\title{
Median arcuate ligament syndrome
}

\author{
FH Ng *, Ophelia KH Wai, Agnes WY Wong, SM Yu
}

Hong Kong Med J 2016;22:184.e3-4

DOI: 10.12809/hkmj154821

\section{Case}

A middle-aged man admitted with abdominal pain and anaemia in December 2015. A computed tomographic (CT) angiogram demonstrated a superior indentation with focal narrowing in the proximal celiac axis (Fig 1). Conventional superior mesenteric arteriogram demonstrated prominent collaterals, and retrograde flow of contrast from the superior mesenteric artery (SMA) to the hepatic arteries (Fig 2). It was likely related to chronic compression of the proximal celiac artery. Low insertion of the median arcuate ligament (MAL) can be found in normal asymptomatic people. In this case, prominent collaterals and the retrograde flow from the SMA supported the diagnosis and may have explained his symptoms. In symptomatic cases, surgical division of the median arcuate ligament is the mainstay of treatment.

\section{Discussion}

The MAL is a fibrous arch that unites the diaphragmatic crura on either side of the aortic hiatus. The crura pass superior and anterior to surround the aortic opening and to join the central tendon of the diaphragm. The ligament usually passes superior to the origin of the celiac axis. The insertion of the ligament may be low and therefore crossover the proximal portion of the celiac axis, causing a characteristic indentation. If it is significantly compressed on the celiac axis, this will compromise vascular flow and produce symptoms.

The MAL syndrome was first described in 1963 by Harjola ${ }^{1}$ and in 1965 by Dunbar et al. ${ }^{2}$ The definition of the syndrome relies on a combination of both clinical and radiographic features. Clinically, they described a classical triad of chronic postprandial abdominal pain, epigastric bruit, and weight loss. ${ }^{3,4}$ Extrinsic compression of the celiac trunk by the MAL occurs in $10 \%$ to $24 \%$ of patients. ${ }^{1}$ Usually, patients are asymptomatic and the classical triad is not always present, presumably due to collateral supply from the superior mesenteric circulation..$^{1,2}$ The disease typically occurs in young patients and is more common in thin women who may present with epigastric pain and weight loss. ${ }^{1}$ The abdominal pain may be associated with eating, but not always. ${ }^{1}$ On physical examination, an abdominal bruit that

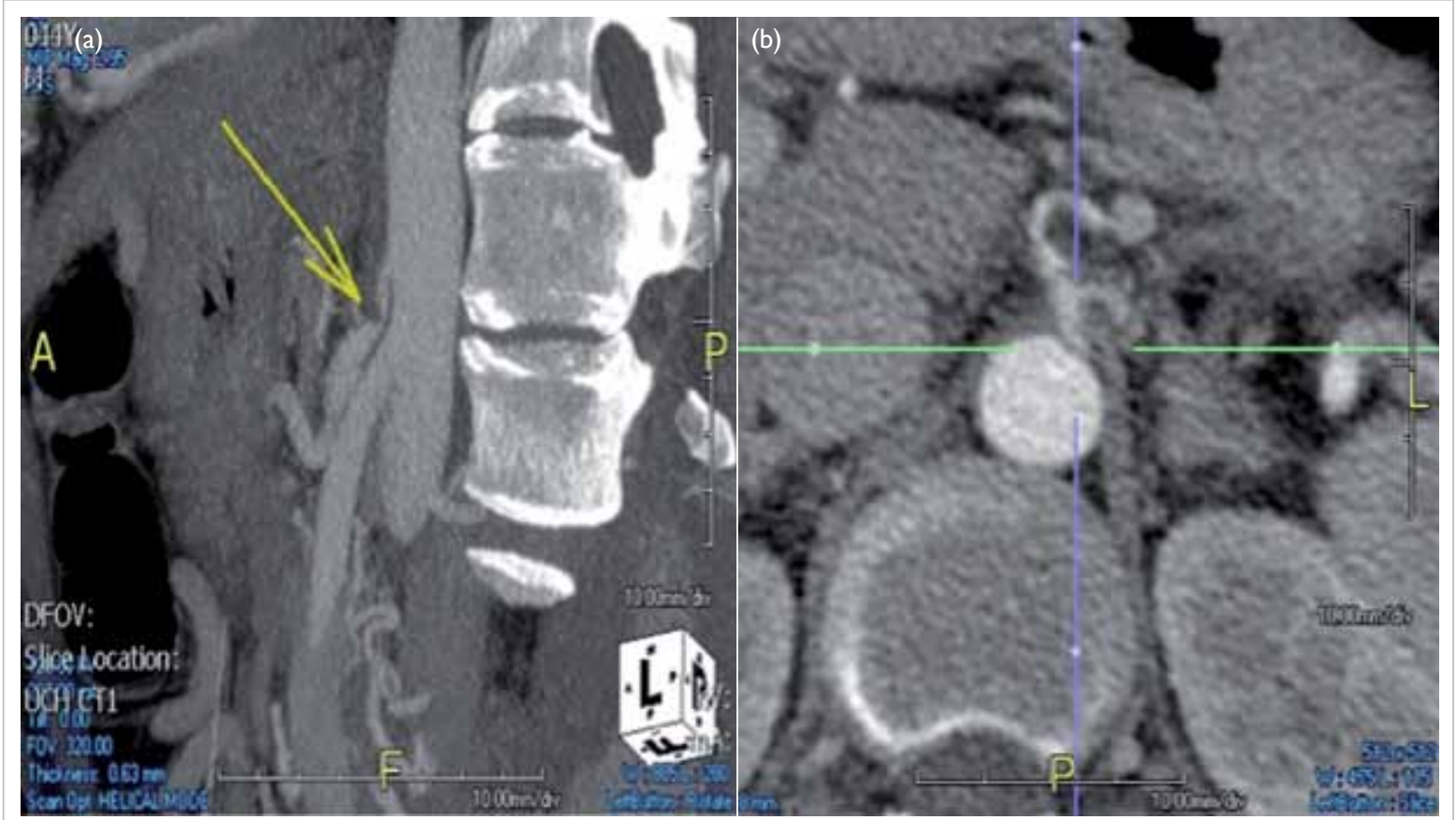

FIG I. (a) Reformatted computed tomographic (CT) image showing the characteristic focal narrowing of the celiac artery with a hooked appearance (arrow) which is compressed by the median arcuate ligament (MAL). (b) The CT axial image again demonstrating the compression by the MAL 


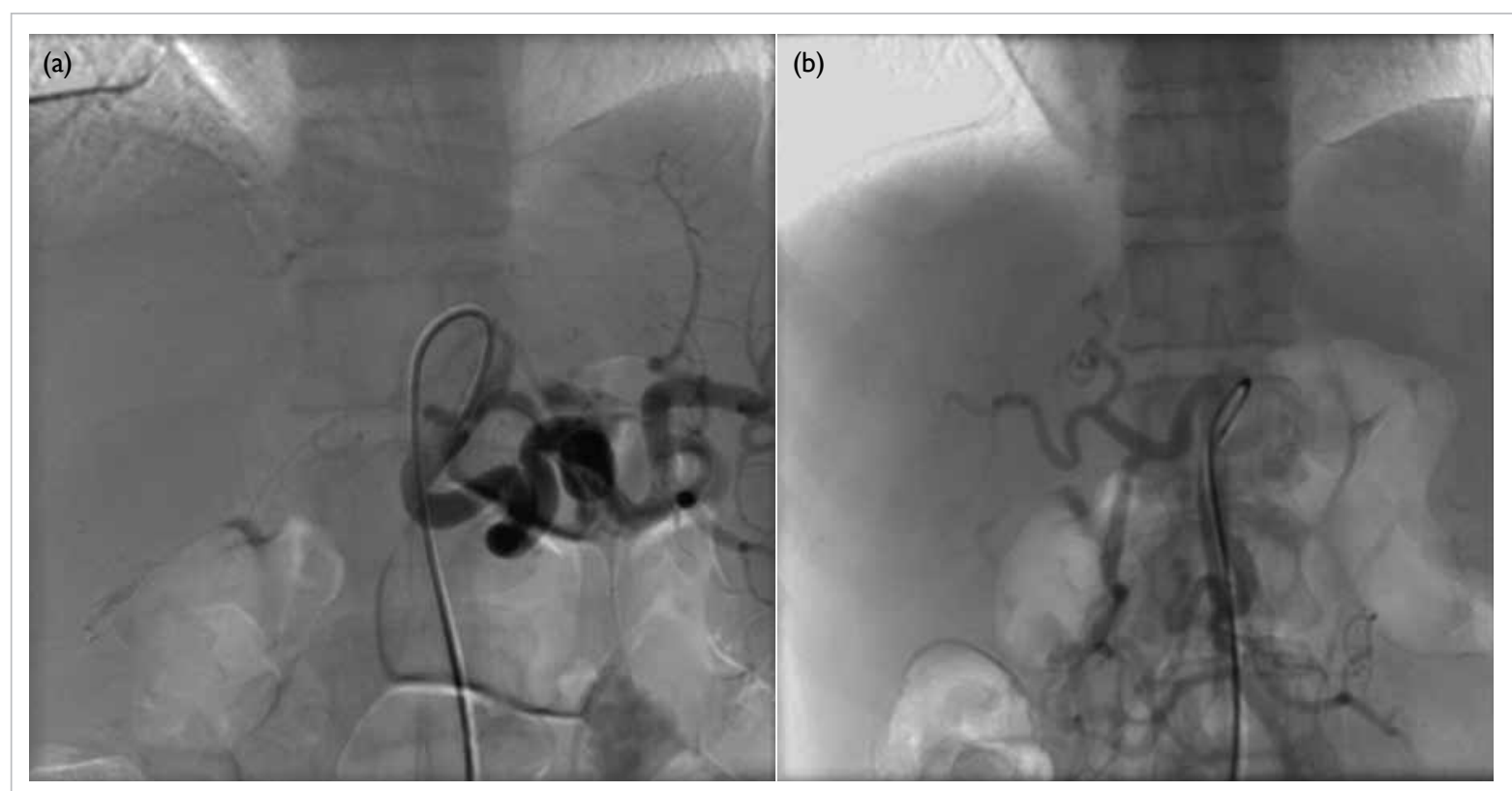

FIG 2. (a) Celiac angiogram showing post-stenotic prominent splenic artery and collaterals. (b) Angiogram of superior mesenteric artery (SMA) showing retrograde flow to celiac axis from the SMA via the pancreaticoduodenal arcade

varies with respiration may be audible in the midepigastric region. Symptoms are thought to arise from compression of the celiac axis with consequent compromised blood flow.

The diagnosis of celiac artery compression is traditionally made following conventional angiography. The use of thin-section multidetector CT and three-dimensional imaging techniques has greatly improved the ability to non-invasively obtain detailed images of the mesenteric vessels. Compression of the celiac axis by the MAL produces characteristic findings visible on $\mathrm{CT}$ angiography. Computed tomographic angiography can play a role in the diagnosis of this condition by demonstrating the characteristic focal narrowing of the celiac artery (Fig 1) with a hooked appearance that distinguishes this condition from other causes of celiac artery narrowing, such as atherosclerotic disease. Indentation of the origin of coeliac artery is exacerbated during the expiratory phase. Repeating CT on inspiration can often distinguish clinically significant narrowing from transient compression seen only during expiration in some patients, and is how most abdominal CT studies are performed. ${ }^{1}$

The majority of affected patients have no symptoms, thus radiographic finding of celiac axis compression alone may not be significant, unless it is correlated with clinical symptoms. Severe compression occurs in approximately $1 \%$ of patients. ${ }^{1}$ Severe stenosis will result in post-stenotic dilatation, and in some cases, the celiac axis will be fed by the SMA via the pancreaticoduodenal arcade. This was evident on the angiogram of our patient with prominent collaterals and retrograde flow from the SMA (Fig 2). His CT angiogram showed a characteristic hooked focal narrowing at the superior proximal celiac artery (Fig 1).

The surgical management of MAL syndrome is controversial. ${ }^{1,2}$ Surgical treatment in severe cases is advocated, particularly in cases with post-stenotic dilatation and collateral vessels (Fig 2), by division of the ligament. A laparoscopic approach is being increasingly adopted. Celiac angioplasty and stenting by endovascular means may be a future hot topic. ${ }^{2}$

$\mathrm{FH} \mathrm{Ng}{ }^{*}, \mathrm{MB}, \mathrm{ChB}, \mathrm{FRCR}$

OKH Wai, MB, ChB, FRCR

AWY Wong, MB, ChB, FRCR

SM Yu, MB, ChB, FRCR

Department of Radiology and Organ Imaging, United Christian Hospital, Kwun Tong, Kowloon, Hong Kong

* Corresponding author: nfh667@ha.org.hk

\section{References}

1. Harjola PT. A rare obstruction of the coeliac artery: report of a case. Ann Chir Gynaecol Fenn 1963;52:547-50.

2. Dunbar JD, Molnar W, Beman FF, Marable SA. Compression of the celiac artery and abdominal angina. Am J Roentgenol Radium Ther Nucl Med 1965;95:73144.

3. Horton KM, Talamini MA, Fishman EK. Median arcuate ligament syndrome: evaluation with CT angiography. Radiographics 2005;25:1177-82.

4. Duffy AJ, Panait L, Eisenberg D, Bell RL, Roberts KE, Sumpio B. Management of median arcuate ligament syndrome: a new paradigm. Ann Vasc Surg 2009;23:778-84. 